\title{
CHIASMA STUDIES IN STRUCTURAL HYBRIDS. VIII. FURTHER EVIDENCES FOR CHIASMA FORMATION BY CROSSING-OVER IN RECIPROCAL TRANSLOCATIONS OF SCILLA SCILLOIDES
}

\author{
SHOZO NODA \\ Biological Institute, Osaka Gakuin University, Suita, Osaka
}

Received October 5, 1966

The conformity between frequency of the chiasma formation in the heteromorphic chromosome pair and that of the equational AI separation has previously been ascertained in a heterozygote for reciprocal translocation of Scilla scilloides Druce (Noda 1961). The same findings were reported in the various cases of the reciprocal translocations and deficiency, in plants and animals, in serial articles of the present studies (Kayano 1960, Kayano and Nakamura 1960, Noda 1960, Zen 1961). Such close interrelation can be well interpreted on the basis of the chiasmatype hypothesis. In the present study further evidences for the chiasma formation by the crossing-over were obtained in the four cases of reciprocal translocation in S. scilloides.

\section{OBSERVATIONS}

A complex $S$. scilloides is an aggregate of the eight cytogenetic types constituted of two different genomes $\mathrm{A}(\mathrm{x}=8)$ and $\mathrm{B}(\mathrm{x}=9)$, the former being consisted of eight chromosomes $a_{1}$ to $a_{8}$ and the latter of nine chromosomes $b_{1}$ to $b_{9}$ (Haga and Noda 1958, 1963). In addition to the standard chromosomes a telocentric B-chromosome $f$ and its isochromosome $\mathrm{F}$ are found to present in certain plants (Haga 1961).

Four different types of the translocation heterozygotes were found in the natural populations. The first was found in a cytogenetic type $\mathrm{ABB}$ and to involve a translocation between chromosome $b_{2}$ and $b_{4}$ of the genome $B$, the second in $A A B B$ and to involve a translocation between $a_{2}$ and $a_{4}$ of the genome $A$, and the third and forth in AABB; in the latter two cases chromosomes which participated in the translocations were unidentifiable (Figs. 1-3, Table 1).

Karyotypes and meiotic pairings in the plants dealt with in the present study will be described in detail elsewhere. The same cytological method were employed as described in a previous paper (Noda 1960).

Meiotic pairings of four chromosomes participated in the translocations are presented diagrammatically in Figures 1-3. In the translocations between $b_{2}-b_{4}$ and between $\mathrm{a}_{2}-\mathrm{a}_{4}$, two chromosome pairs, I and II, were clearly distinguishable at MI as well as at AI from one another, but those pairs were unidentifiable in the third and forth transloca- 
Table 1. Standard MI pairing in the heterozygotes for four types of reciprocal translocations

\begin{tabular}{c|c|c|c}
\hline \hline $\begin{array}{c}\text { Cytogenetic } \\
\text { type }\end{array}$ & $\begin{array}{c}\text { Translocation } \\
\text { between }\end{array}$ & $\begin{array}{c}\text { Standard } \\
\text { MI config. }\end{array}$ & \multicolumn{1}{c}{$\begin{array}{c}\text { Plant } \\
\text { from }\end{array}$} \\
\hline ABB & $\mathrm{b}_{2}-\mathrm{b}_{4}$ & $\bigcirc 4+7_{\mathbb{I}}+8_{\mathrm{I}}$ & Usa (Kyushu) \\
$\mathrm{AABB}$ & $\begin{array}{c}\mathrm{a}_{2}-\mathrm{a}_{4} \\
\text { not } \\
\text { identified } \\
\text { not } \\
\text { identified }\end{array}$ & $\bigcirc 4+15_{\mathbb{I}}$ & Iwami (Tyugoku) \\
$\mathrm{AABB}$ & $\bigcirc 4+15_{\mathbb{I}}$ & Yosu (Korea) \\
$\mathrm{AABB}$ & $\bigcirc 4+15_{\mathbb{I}}$ & Isl. Izena (Ryukyus) \\
\hline
\end{tabular}

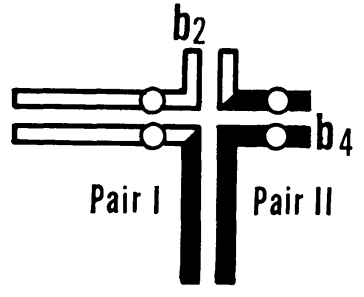

1

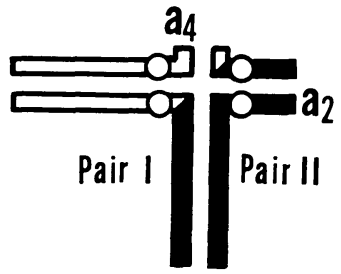

2

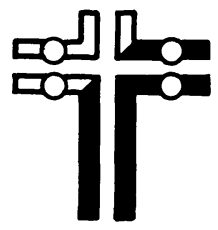

3

Figs. 1-3. Diagrammatic representation of the meiotic pairings in four types of translocation heterozygotes. 1. $\mathrm{b}_{2}-\mathrm{b}_{4}$ translocation (ABB). 2. $\mathrm{a}_{2}-\mathrm{a}_{4}$ translocation (AABB). 3. Translocations in which participated chromosome were unidentifiable (AABB).

tion heterozygotes found in cytogenetic type AABB. Homologous kinetochores appeared separated at MI without exception (Figs. 4, 6-8).

In no case was formation of more than a single chiasma observed in the interstitial segments between the kinetochore and the point of interchange. Formation and nonformation of a single chiasma in the interstitial segment are denoted as IX and OX, and equational and reductional $\mathrm{AI}$ separations of the pair involving this segment as $\mathrm{E}$ and $\mathrm{R}$. In the two translocation heterozygotes involving unidentifiable pairs, the chiasma formation and AI separations were recorded in the same way as in the previous paper; OX-OX, IX-OX, and IX-1X for chiasma formation, and R-R, E-R, and E-E for AI separation (cf. Noda 1961).

In the two pairs of the translocation $b_{2}-b_{4}$ of cytogenetic type $A B B$, there were found nearly no chiasma and no equational AI separation (Figs. 1, 4-5, Table 2). On the contrary, in the case of translocation $\mathrm{a}_{2}-\mathrm{a}_{4}$ found in cytogenetic type AABB, the frequencies of chiasmata per segment conforms statistically with that of AI equational separation per pair; $0.273 \mathrm{X}$ and $0.176 \mathrm{E}$ in pair I, and $0.455 \mathrm{X}$ and $0.412 \mathrm{E}$ in pair II (Figs. 2, 6, Table 2). The same holds true of other two translocations found in cytogenetic type $\mathrm{AABB}$, that is, $0.50 \mathrm{X}$ at $\mathrm{MI}$ and $0.50 \mathrm{E}$ at $\mathrm{AI}$ in one of the two, and $0.494 \mathrm{X}$ and $0.490 \mathrm{E}$ in the remaining one (Figs. 3, 7-9, Table 2). 

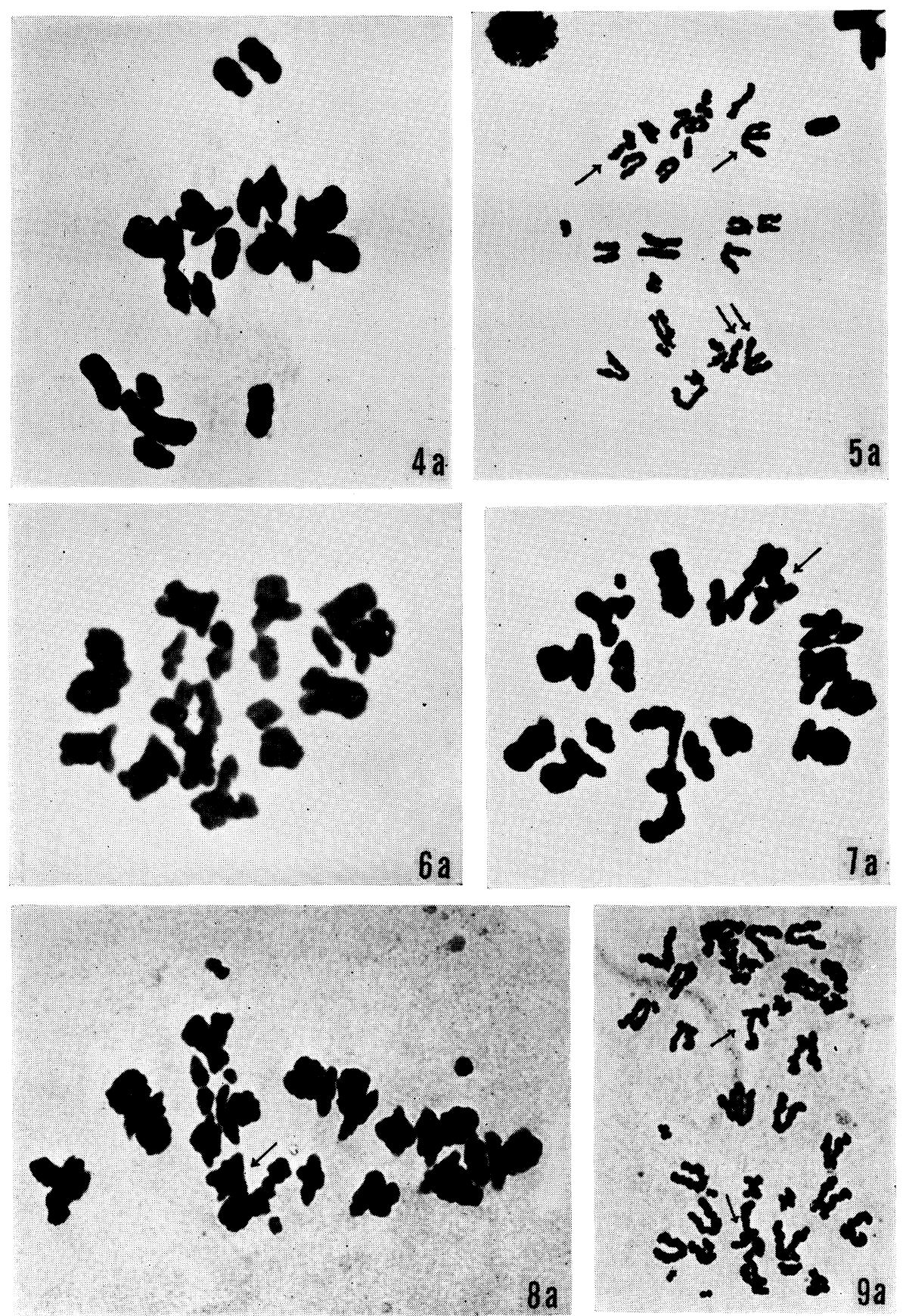

Figs. 4a-9a. 4a, 6a-8a. MI in the translocation heterozygotes, arrows indicate a single chiasma in the interstitial segment. $\times 1200$. 5a, 9a. AI in the translocation heterozygotes, arrows indicate the equational separation. $\times 800$. 4a-5a. Translocation $b_{2}-b_{4}(A B B) .4 a .04+7$ I $+8_{\text {I }}$, OX-OX. 5a. E-E. 6a. $\bigcirc 4+15_{\mathbb{I}}$, OX-OX, in $\mathrm{a}_{2}-\mathrm{a}_{4}$ translocation (AABB). 7a-9a. Translocations in $\mathrm{AABB}$ in which interchanged chromosomes were unidentifiable. $7 \mathrm{a} .1_{\mathrm{N}}+15_{\mathbf{I}}$ $+1 f_{I}$, IX-OX (Yosu). 8a-9a. Translocation (Isl. Izena). 8a. $1_{\mathbb{I}}+15_{\mathbb{I}}+1 f_{I}+2 f_{I}+\bigcirc F$, IX-OX. 9a. E-R, of which reductional separation can not be identified. 


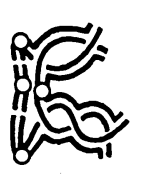

$4 \mathrm{~b}$

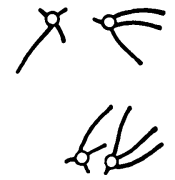

$5 b$

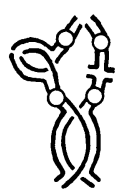

$6 \mathrm{~b}$

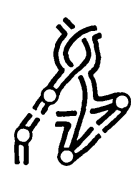

$7 \mathrm{~b}$

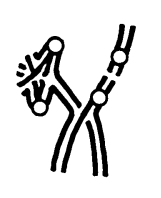

$8 \mathrm{~b}$

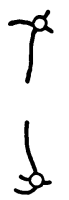

$9 b$

Figs. $4 b-9 b$. Line diagrams of the configurations of the photos given in Figures $4 a-9 a$.

Table 2. Chiasma frequencies in the interstitial segments as compared with those of equational AI separation in the translocation heterozygote in which two pairs are identifiable, above, and not identifiable, below

\begin{tabular}{|c|c|c|c|c|c|c|c|c|c|c|c|c|c|c|c|}
\hline \multirow{2}{*}{$\begin{array}{l}\text { Cytogenetic } \\
\text { type }\end{array}$} & \multirow{2}{*}{$\begin{array}{c}\text { Transloca- } \\
\text { tion }\end{array}$} & \multirow{2}{*}{ Pair } & \multicolumn{5}{|c|}{ MI } & \multicolumn{5}{|c|}{ AI } & \multirow{2}{*}{$\chi^{2}$} & \multirow{2}{*}{\multicolumn{2}{|c|}{ D. F. }} \\
\hline & & & $\begin{array}{l}\text { Segm. } \\
\text { obs. }\end{array}$ & $0 \mathrm{X}$ & $1 \mathrm{X}$ & $\mathrm{Xta} / \mathrm{s}$ & segm. & $\begin{array}{l}\text { Pair } \\
\text { obs. }\end{array}$ & $\mathrm{R}$ & $\mathrm{E}$ & $\mathrm{E} / \mathrm{p}$ & & & & \\
\hline \multirow{2}{*}{$\mathrm{ABB}$ (Usa) } & \multirow{2}{*}{$b_{2}-b_{4}$} & I & 33 & 33 & 0 & 0.0 & & 27 & 27 & 0 & 0. & & 0.0 & & 1 \\
\hline & & II & 33 & 32 & 1 & 0.0 & 030 & 27 & 27 & 0 & 0. & & 0.0 & & 1 \\
\hline \multirow{2}{*}{ AABB (Iwami) } & \multirow{2}{*}{$a_{2}-a_{4}$} & I & 11 & 8 & 3 & & 273 & 17 & 14 & 3 & 0. & 176 & 0.8 & & 1 \\
\hline & & II & 11 & 6 & 5 & 0.4 & 455 & 17 & 10 & 7 & & 412 & 0.1 & & 1 \\
\hline \multirow{2}{*}{$\begin{array}{l}\text { Cytogenetic } \\
\text { type }\end{array}$} & \multirow{2}{*}{$\begin{array}{c}\text { Transloca- } \\
\text { tion }\end{array}$} & \multicolumn{6}{|c|}{ MI } & \multicolumn{6}{|c|}{ AI } & \multirow{2}{*}{$\chi^{2}$} & \multirow{2}{*}{ D.F. } \\
\hline & & $\begin{array}{c}\text { Segm } \\
\text { obs. }\end{array}$ & n. $0 \mathrm{X}-0 \mathrm{X}$ & & $-0 \mathrm{X}$ & $1 \mathrm{X}-1 \mathrm{X}$ & $\begin{array}{l}\mathrm{Xta} / \\
\text { segm }\end{array}$ & $\begin{array}{l}\text { Pair } \\
\text { obs. }\end{array}$ & $\mathrm{R}-\mathrm{I}$ & E-R & E-E & $\mathrm{E} / \mathrm{pai}$ & & & \\
\hline AABB (Yosu) & $\begin{array}{c}\text { not } \\
\text { identified }\end{array}$ & 128 & 6 & & 16 & 6 & 0.50 & 20 & 0 & 20 & 0 & 0.50 & & 0.56 & 1 \\
\hline AABB (Izena) & $\begin{array}{c}\text { not } \\
\text { identified }\end{array}$ & 500 & 46 & & 14 & 40 & 0.494 & 50 & 6 & 39 & 5 & 0.49 & & 1.46 & 1 \\
\hline
\end{tabular}

The $\chi^{2}$-test for the confirmity between the mean chiasma frequency and the mean frequency of equational $\mathrm{AI}$ separation gives the value $\mathrm{P}>0.05$ without exception.

\section{CONCLUSION AND SUMMARY}

The heterozygotes for four types of the reciprocal translocations were found in the natural populations of $S$. scilloides consisting of genome $\mathrm{A}(\mathrm{x}=8)$ and $\mathrm{B}(\mathrm{x}=9)$. One of those was involved in cytogenetic type ABB $\left(\bullet 4+7_{\text {II }}+8_{I}\right)$, and three in AABB $(\bullet 4+$ 15II). The frequencies of chiasmata observed at $\mathrm{MI}$ in the interstitial segments between kinetochore and the point of interchange conformed very well to that of equational AI separations of the pairs involving these segments.

The same parallelism has also been confirmed in the heterozygotes for pericentric inversion in S. scilloides (Noda 1965). Furthermore, in the same species, a single chiasma was clearly observed to be formed at the segment between two unpaired loops in the asymmetrical bivalent resulted from the intra-arm transposition (Noda 1962). These findings support the chiasmatype hypothesis accounting for the origin of the 
cytological configuration chiasma (cf. Darlington 1965).

The writer wishes to express his appreciation to Professor Tutomu Haga, Kyushu University, for his helpful suggestions and criticisms during the course of this study. The writer is also grateful to Dr. M. Kamura, Ryukyu Unversity, and Mr. Y. Honda, Turumi-ga-Oka High School, for their courtesy in providing the materials used in the present study.

\section{LITERATURE CITED}

Darlington, C. D., 1965 Recent advances in cytology. Part I. 2nd ed. Churchill, London.

Haga, T., and S. Noda, 1958 Cytogenetic population structure of Scilla scilloides Druce: A complex. Proc. Xth Intern. Congr. Genetics 2: 109.

Haga, T., 1961 Intra-individual variation in number and linear patterning of the chromosomes. I. B-chromosomes in Rumex, Paris, and Scilla. Proc. Japan Acad. 37: 627-632.

Haga, T., and S. Noda, 1963 Population structure and dynamics in a complex Scilla scilloides (Liliaceae). Genetics Today 1: 150-151. Pergamon Press, Oxford.

Kayano, H., 1960 Chiasma studies in structural hybrids. III. Reductional and equational separation in Disporum sessile. Cytologia 25: 461-467.

Kayano, H., and K. Nakamura, 1960 Chiasma studies in structural hybrids. V. Heterozygotes for a centric fusion and for a translocation in Acrida lata. Cytologia 25: 476-480.

Noda, S., 1960 Chiasma studies in structural hybrids. II. Reciprocal translocation in Lilium maximowiczii. Cytologia 25: 456-460.

Noda, S., 1961 Chiasma studies in structural hybrids. VII. Reciprocal translocation in Scilla scilloides. Cytologia 26: 74-77.

Noda, S., 1962 Chiasmata in intra-arm transposition heterozygote in Scilla scilloides. CIS, Tokyo 3 : 21-22.

Noda, S., 1965 Chiasma studies in structural hybrids. IX. Pericentric inversion in Scilla scilloides. Japan J. Genetics 40: 410. (Abstract, in Japanese).

Zen, S., 1961 Chiasma studies in structural hybrids. VI. Heteromorphic bivalent and reciprocal translocation in Allium fistulosum. Cytologia 26: 67-73. 